\title{
Physical activity and metabolic health in chronic kidney disease: a cross-sectional study
}

\author{
Wilson Bowlby ${ }^{1}$, Leila R. Zelnick², Connor Henry², Jonathan Himmelfarb², Steven E. Kahn ${ }^{3,4}$, Bryan Kestenbaum², \\ Cassianne Robinson-Cohen ${ }^{2}$, Kristina M. Utzschneider ${ }^{3,4}$ and lan H. de Boer ${ }^{2,3^{*}}$
}

\begin{abstract}
Background: Patients with chronic kidney disease (CKD) are at high risk of progression to end stage renal disease and cardiovascular events. Physical activity may reduce these risks by improving metabolic health. We tested associations of physical activity with central components of metabolic health among people with moderate-severe non-diabetic CKD.

Methods: We performed a cross-sectional study of 47 people with CKD (estimated GFR $<60 \mathrm{ml} / \mathrm{min} / 1.73 \mathrm{~m}^{2}$ ) and 29 healthy control subjects. Accelerometry was used to measured physical activity over 7 days, the hyperinsulinemiceuglycemic clamp was used to measure insulin sensitivity, and DXA was used to measured fat mass. We tested associations of physical activity with insulin sensitivity, fat mass, blood pressure, serum lipid concentrations, and serum high sensitivity C-reactive protein concentration using multivariable linear regression, adjusting for possible confounding factors.
\end{abstract}

Results: Participants with CKD were less active than participants without CKD (mean (SD) 468.1 (233.1) versus 662.3 (292.5) counts per minute) and had lower insulin sensitivity (4.1 (2.1) versus $5.2(2.0(\mathrm{mg} / \mathrm{min}) /(\mu \mathrm{U} / \mathrm{mL}))$, higher fat mass (32.0 (11.4) versus $29.4(14.8) \mathrm{kg}$ ), and higher triglyceride concentrations (153.2 (91.6) versus 99.6 (66.8) mg/dL). With adjustment for demographics, comorbidity, medications, and estimated GFR, each two-fold higher level of physical activity was associated with a $0.9(\mathrm{mg} / \mathrm{min}) /(\mu \mathrm{U} / \mathrm{mL})$ higher insulin sensitivity $(95 \% \mathrm{Cl} 0.2,1.5, p=0.006)$, an $8.0 \mathrm{~kg}$ lower fat mass $(-12.9,-3.1, p=0.001)$, and a $37.9 \mathrm{mg} / \mathrm{dL}$ lower triglyceride concentration $(-71.9,-3.9, p=0.03)$. Associations of physical activity with insulin sensitivity and triglycerides did not differ significantly by CKD status ( $p$-values for interaction $>0.3$ ).

Conclusions: Greater physical activity is associated with multiple manifestations of metabolic health among people with moderate-severe CKD.

Keywords: Chronic kidney disease, Physical activity, Metabolism, Insulin resistance, Obesity, Triglycerides

\section{Background}

People with chronic kidney disease (CKD) are at high risk of cardiovascular disease (CVD) [1]. Reduced sensitivity to the actions of insulin, i.e. insulin resistance, is one mechanism through which CKD may promote CVD [2]. Patients with CKD are often insulin resistant [3-5].

\footnotetext{
*Correspondence: ideboer@Nephrology.washington.edu

${ }^{2}$ Division of Nephrology and Kidney Research Institute, University of

Washington, Seattle, WA, USA

${ }^{3}$ VA Puget Sound Health Care System, Seattle, WA, USA

Full list of author information is available at the end of the article
}

Insulin resistance is a central component of the metabolic syndrome, an adverse metabolic milieu that includes obesity, hyperglycemia, dyslipidemia, and hypertension and is associated with activation of the renin-angiotensinaldosterone system, oxidative stress, inflammation, and endothelial dysfunction [2, 6, 7]. Insulin resistance and these interrelated metabolic abnormalities have been associated with increased risks of atherosclerosis and cardiovascular events as well as progression of CKD to end stage renal disease [8-11]. 
Interventions that aim to increase physical activity are promising approaches to improve metabolic health and clinical outcomes in CKD. In people without CKD, physical activity reduces adiposity and mitigates the metabolic syndrome $[12,13]$. In the CKD population, physical activity is often low, and greater higher physical activity is associated decreased risks of CKD progression [14] and mortality [15]. However, few studies have assessed the metabolic pathways through which physical activity may lead to improved outcomes in CKD.

We quantified physical activity using accelerometers in a cross-sectional study of people with and without moderate-severe CKD, none of whom had clinical diabetes [4]. We examined relationships of objectively measured physical activity with insulin sensitivity quantified using the gold standard hyperinsulinemic-euglycemic clamp [16] and with related measures of metabolic health. We hypothesized that higher levels of physical activity would be associated with greater insulin sensitivity, reduced adiposity, an improved lipid profile, lower blood pressure, and lower levels of systemic inflammation.

\section{Methods}

\section{Study population}

The Study of Glucose and Insulin in Renal Disease (SUGAR) is a cross-sectional study of glucose and insulin metabolism among individuals who have moderatesevere nondiabetic CKD and healthy control individuals who do not have kidney disease [4]. Participants were recruited from nephrology and primary care clinics associated with the University of Washington and neighboring institutions in Seattle, Washington, from 2011 to 2104 (Additional file 1: Figure S1). SUGAR enrolled 59 participants with non-diabetic stage 3-5 CKD (estimated glomerular filtration rate $<60 \mathrm{~mL} / \mathrm{min} / 1.73 \mathrm{~m}^{2}$ not treated with dialysis) and 39 control subjects (estimated glomerular filtration rate $>60 \mathrm{~mL} / \mathrm{min} / 1.73 \mathrm{~m}^{2}$ ) with comparable distributions of age, sex, and race. Exclusion criteria for both groups included age $<18$ years, a clinical diagnosis of diabetes, maintenance dialysis or fistula in place, history of kidney transplantation, use of medications known to reduce insulin sensitivity (including corticosteroids and immunosuppressants), fasting serum glucose $\geq 126 \mathrm{mg} / \mathrm{dL}$, and hemoglobin $<10 \mathrm{~g} / \mathrm{dL}$. For this study, we included 76 SUGAR participants who collected accelerometry data for $\geq 480 \mathrm{~min}$ on each of three or more days, excluding 12 who did not perform accelerometry and 10 whose accelerometry data were insufficient.

\section{Accelerometry}

We quantified physical activity using the ActiGraph GT3X. The GT3X measures movement in three planes ( $\mathrm{x}$-axis, $\mathrm{y}$-axis, $\mathrm{z}$-axis). Movements in all three planes were summed for each $60-\mathrm{s}$ time period (1-min epoch) to generate movement in counts per minute (CPM). Study participants were asked to wear an accelerometer at their waist at all times through a consecutive 7-day period, including weekdays and weekend days, removing the accelerometer only during sleep and water-based activities. ActiLife v5.10.0 was used to upload, clean, and analyze collected data.

Accelerometry data reduction and analysis were based on prior reports $[17,18]$. Participants were included in analyses if they wore an accelerometer for at least $8 \mathrm{~h}$ (approximately $60 \%$ of wake time) on at least 3 days (approximately half of the requested number of wear days). Non-wear periods were defined as intervals of at least 60 min during which no more than 2 min registered greater than zero CPM and no single minute registered $>100$ CPM. For each sufficient participant-day, CPM was calculated as the total number of movement counts divided by total wear time. For each participant with at least three qualified wear days, we calculated mean CPM, the primary exposure for this study, as the simple mean of CPM for all days with sufficient data. As secondary exposures, we also examined proportions of time spent active (i.e. non-sedentary) and in moderate-vigorous physical activity [18]. For each minute of wear time, $\leq 59$ CPM was classified as sedentary, and $>59$ CPM was classified as active.

Participants also completed the Human Activity Profile (HAP) as a parallel assessment of self-reported physical activity, and the adjusted HAP score was used as a third exposure [19].

\section{Metabolic health}

Insulin sensitivity was measured using by hyperinsulinemiceuglycemic clamp [4], based on the method of DeFronzo et al. [16]. Participants were admitted to the University of Washington Clinical Research Center after an overnight fast. An insulin infusion was administered as a prime (160 $\mathrm{mU} / \mathrm{m}^{2} / \mathrm{min}$ for $5 \mathrm{~min}$ ) followed by a constant infusion $\left(80 \mathrm{mU} / \mathrm{m}^{2} / \mathrm{min}\right)$. Blood glucose was measured every $5 \mathrm{~min}$, and a variable rate of unlabeled $20 \%$ dextrose was infused to maintain blood glucose at approximately $90 \mathrm{mg} / \mathrm{dL}$. Beginning 120-150 min after initiation of the insulin infusion, the dextrose infusion rate was held constant for $30 \mathrm{~min}$, over which three steady-state plasma samples were obtained $15 \mathrm{~min}$ apart. Plasma concentrations of insulin and glucose were measured by two site immuneenzymometric assay (Tosoh 2000 auto-analyzer) and the glucose hexokinase method (Roche Module P Chemistry autoanalyzer), respectively. The dextrose concentration of the infusate was similarly quantified. Insulin sensitivity (SI) was calculated as (glucose disposal rate adjusted for drift in plasma glucose $\mathrm{x}$ concentration of infused glucose)/(insulin concentration at steady state - fasting insulin concentration) [16]. We calculated HOMA-IR from fasting insulin 
and glucose concentrations as an alternate assessment of insulin resistance [20].

Body composition (fat mass and fat-free mass) was measured by DXA (GE Lunar or Prodigy and iDXA, EnCore Software versions 12.3 and 14.1). Quality assurance procedures were followed on a daily basis as the calibration block and spine phantom were scanned and the analyzed readings were ensured to be within $1.5 \%$ of the actual measured quantities.

Blood pressure (BP) was measured on two occasions (immediately prior to the hyperinsulinemic-euglycemic clamp and approximately 1 week later). On each occasion, $\mathrm{BP}$ was measured three times, $5 \mathrm{~min}$ apart, in the seated position. The mean values of the final two measurements from each visit were used for analysis.

High sensitivity C-reactive protein (CRP), total cholesterol, HDL cholesterol, and trigylcerides were measured on the Beckman DXC600 automated chemistry platform systems. SYNCHRON systems quantitatively measures C-reactive protein, total cholesterol, HDL cholesterol, and triglycerides in human serum or plasma by rate turbidity. For all assays, interassay coefficients of variation were less than $5 \%$.

\section{Covariates}

Demographics and medical history were self-reported. Prevalent cardiovascular disease was defined as a physician diagnosis of myocardial infarction, stroke, resuscitated cardiac arrest, or heart failure or a history of coronary or cerebral revascularization [4]. Medications were ascertained by the inventory method. Serum creatinine and cystatin $C$ were measured in fasting serum collected immediately prior to the clamp using a Beckman DxC automated chemistry analyzer. Creatinine concentration was traced to isotope dilution mass spectrometry values and cystatin C concentration was calibrated to ERM-DA471/ IFCC. GFR was estimated from creatinine and cystatin C concentrations using the CKD-EPI formula [21]. Urine albumin was measured using a turbidimetric method on a Beckman Dxc automated chemistry analyzer (interassay coefficient of variation $0.8-1.7 \%$ ).

\section{Statistical analysis}

Participant characteristics and measures of metabolic health were summarized by tertiles of physical activity. Scatterplots with linear regression lines were used to graphically examine associations of physical activity with metabolic health outcomes, stratified by CKD status. Multivariable linear regression was used to test associations of every doubling of physical activity with metabolic health outcomes, assessing the full study population together for primary analyses. A series of nested models was created accounting for potential confounding covariates. The first model adjusted for demographic data: age (continuous variable), sex, and race (white/black/ other). The second model additionally adjusted for cardiovascular disease and eGFR (continuous variable). The third model additionally adjusted for fat mass (continuous variable), which was considered either a confounder or mediator of the associations of interest. Medications were included in models if they directly affect the metabolic variable being assessed. Specifically, lipid-lowering medication classes were included as covariates when modeling triglycerides or HDL cholesterol as an outcome and antihypertensive medications (yes/no categorical variable plus number of medications modeled as a continuous variable) when modeling BP as an outcome. Missing data were multiply imputed and combined using Rubin's rules. Interaction terms were used to test for differences in associations by CKD status. Twoway interactions were tested using multiplicative terms in the regression models with Wald tests to evaluate significance. All analyses were performed using Stata 14.0 and $R$ version 3.2.1 [22]. Study investigators and staff were not blinded to CKD status, accelerometer data, or measures of metabolic health.

\section{Results}

Of the 76 SUGAR participants included in this study, mean age was 62.6 years, $44.7 \%$ were female, and race was self-reported as black for $14.5 \%$ and Asian or Pacific Islander for 5.3\% (Table 1). 47 participants had CKD and 29 did not. Characteristics of the 76 SUGAR participants included in this analysis were similar to those of the 22 SUGAR participants excluded from this analysis (Additional file 1: Table S1). Participants with greater physical activity tended to be younger, weighed less, and had a higher eGFR (Table 1). Among participants with CKD, mean eGFR was $38.7 \mathrm{~mL} / \mathrm{min} / 1.73 \mathrm{~m}^{2}$ and median AER was $39.2 \mathrm{mg} / 24 \mathrm{~h}$ (Additional file 1: Table S2). Participants with CKD were less physically active than participants without CKD (Fig. 1 and Additional file 1: Table S2).

Physical activity was positively correlated with insulin sensitivity and serum HDL cholesterol concentration and negatively correlated with fasting insulin concentration, HOMA-IR, fat mass, SBP, serum CRP and triglyceride concentrations (Table 2). Adjusting for demographics, cardiovascular disease, and eGFR (Model 2) each doubling of CPM was associated with a $0.9(\mathrm{mg} / \mathrm{min}) /(\mu \mathrm{U} / \mathrm{mL})$ higher insulin sensitivity (95\% CI $0.2,1.5(\mathrm{mg} / \mathrm{min}) /(\mu \mathrm{U} / \mathrm{mL})$, $p=0.006)$, an $8 \mathrm{~kg}$ lower fat mass (95\% CI $-12.9,-3.1 \mathrm{~kg}$, $p=0.001)$, and a $37.9 \mathrm{mg} / \mathrm{dL}$ lower triglyceride concentration (95\% CI $-71.9,-3.9 \mathrm{mg} / \mathrm{dL}, p=0.03)$ (Table 3). With further adjustment for fat mass (Model 3), the associations of physical activity with insulin sensitivity and triglycerides were modestly attenuated, and only the association with insulin sensitivity remained statistically significant (0.7 
Table 1 Characteristics of SUGAR participants, by physical activity

\begin{tabular}{|c|c|c|c|}
\hline & \multicolumn{3}{|l|}{ Physical activity } \\
\hline & $\begin{array}{l}\text { Tertile } 1 \\
(\leq 375 \text { CPM) }\end{array}$ & $\begin{array}{l}\text { Tertile } 2 \\
(375<\text { CPM } \leq 631)\end{array}$ & $\begin{array}{l}\text { Tertile } 3 \\
(>631 \text { CPM) }\end{array}$ \\
\hline $\mathrm{N}$ & 25 & 25 & 26 \\
\hline \multicolumn{4}{|l|}{ Demographics: } \\
\hline Age (years) & $69.5(10.5)$ & $63.0(12.5)$ & $58.1(11.2)$ \\
\hline Female sex & $9(36)$ & $11(44)$ & $14(54)$ \\
\hline \multicolumn{4}{|l|}{ Race } \\
\hline White & $20(80)$ & $21(84)$ & $20(77)$ \\
\hline Black & $4(16)$ & $2(8)$ & $5(19)$ \\
\hline Other & $1(4)$ & $2(8)$ & $1(4)$ \\
\hline \multicolumn{4}{|l|}{ Medical history \& lifestyle: } \\
\hline Cardiovascular disease & $13(52)$ & $2(8)$ & $3(12)$ \\
\hline Current smoking & $5(20)$ & $1(4)$ & $5(19)$ \\
\hline Physical activity (adjusted activity score), median & $67.0(57.0-73.0)$ & $76.0(71.0-82.0)$ & $78.5(74.5-82.8)$ \\
\hline Average Sedentary vs Active Time (\%) & 74.5 & 63.0 & 49.8 \\
\hline \multicolumn{4}{|l|}{ Medication use: } \\
\hline Any antihypertensive medication & $20(80)$ & $16(64)$ & $16(62)$ \\
\hline Number of antihypertensive medications & $2.3(1.5)$ & $1.5(1.8)$ & $1.3(1.5)$ \\
\hline Any lipid-lowering medication & $9(36)$ & $8(32)$ & $5(19)$ \\
\hline Statin & $9(36)$ & $8(32)$ & $4(15)$ \\
\hline Fibrate & $3(12)$ & $1(4)$ & $1(4)$ \\
\hline Niacin & $2(8)$ & $0(0)$ & $1(4)$ \\
\hline \multicolumn{4}{|l|}{ Physical characteristics: } \\
\hline Height (cm) & $172.5(9.3)$ & $170.5(10.0)$ & $173.5(11.8)$ \\
\hline Weight (kg) & $94.9(20.1)$ & $85.8(15.4)$ & $80.1(20.8)$ \\
\hline Fat mass (kg) & $35.7(13.3)$ & $31.2(12.4)$ & $26.3(11.3)$ \\
\hline BMI $\left(\mathrm{kg} / \mathrm{m}^{2}\right)$ & $31.8(6.2)$ & $29.6(5.3)$ & $26.4(5.3)$ \\
\hline Systolic blood pressure (mm Hg) & $135.1(14.4)$ & $130.7(12.1)$ & $124.3(17.2)$ \\
\hline Diastolic blood pressure (mm Hg) & $78.0(9.6)$ & $79.9(8.4)$ & $77.4(11.3)$ \\
\hline \multicolumn{4}{|l|}{ Laboratory data: } \\
\hline Serum creatinine $(\mathrm{mg} / \mathrm{dL})$, median & $1.6(1.2-1.9)$ & $1.4(1.0-1.8)$ & $1.0(0.8-1.5)$ \\
\hline Serum cystatin C (mg/L), median & $1.6(1.1-2.0)$ & $1.2(1.0-1.6)$ & $1.0(0.8-1.4)$ \\
\hline Estimated GFR $\left(\mathrm{mL} / \mathrm{min} / 1.73 \mathrm{~m}^{2}\right)$ & $44.7(21.7)$ & $54.8(28.4)$ & $71.6(26.5)$ \\
\hline $\mathrm{eGFR}<60 \mathrm{~mL} / \mathrm{min} .1 .73 \mathrm{~m}^{2}$ & $21(84)$ & $15(60)$ & $11(42)$ \\
\hline Urine AER, (mg/24 h) median & $24.6(8.2-137.4)$ & $9.7(5.3-91.7)$ & $8.9(5.6-95.4)$ \\
\hline
\end{tabular}

Mean (SD) presented for continuous variables, and median (IQR) as noted; $N(\%)$ presented for all categorical variables. Values were missing for fat mass $(N=4)$ and Urine AER $(N=3)$. CPM counts per minute, GFR glomerular flow rate, AER Albumin excretion rate

$(\mathrm{mg} / \mathrm{min}) /(\mu \mathrm{U} / \mathrm{mL})$ per doubling of CPM, 95\% CI 0, 1.4 $(\mathrm{mg} / \mathrm{min}) /(\mu \mathrm{U} / \mathrm{mL}), p=0.04)$. Associations of physical activity with SBP, HDL cholesterol, and CRP were not significant in adjusted analyses. When mean CPM was replaced with active time (versus sedentary time) or moderate-vigorous as the exposure of interest, the results were similar with no significant changes to interpretation (Additional file 1: Tables S3-S5). When mean
CPM was replaced with Adjusted Human Activity Profile score (HAP) as the primary exposure of interest, associations with insulin sensitivity and triglycerides were weaker (Additional file 1: Table S6).

Compared to non-CKD control subjects, participants with CKD had lower mean insulin sensitivity $(-1.1(\mathrm{mg} /$ $\mathrm{min}) /(\mu \mathrm{U} / \mathrm{mL}))$, higher mean total fat mass $(+2.6 \mathrm{~kg})$, and higher mean triglycerides (+53.6 mg/dL) (Table 4). 

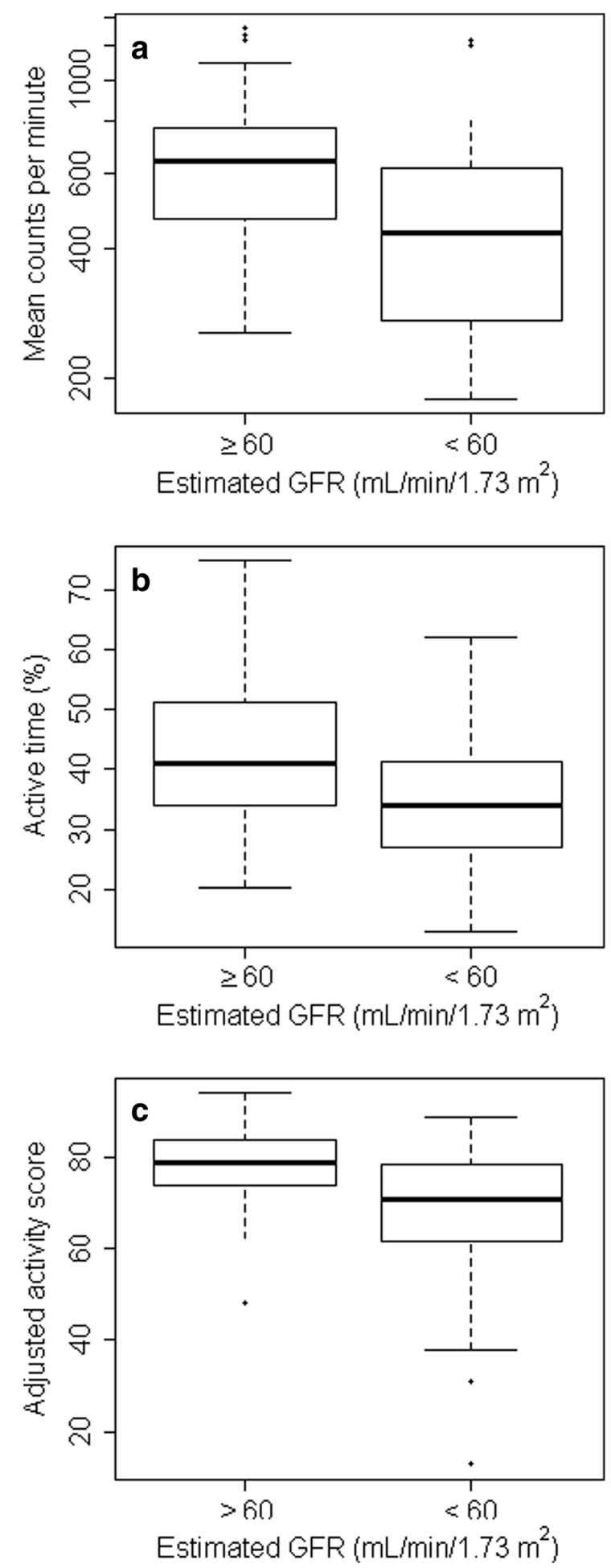

Fig. 1 Physical activity among participants with and without CKD. Boxplots compare the physical activity of non-CKD vs CKD participants. Physical activity was quantified as accelerometry counts per minute (panel a), accelerometry active time (panel b), or human activity profile adjusted activity score (panel c). Box plots display median with the 25 and 75 th percentiles, with participants outside 1.5 times the IQR noted as data points
The associations of physical activity with insulin sensitivity and triglycerides did not differ significantly among participants with and without CKD (Fig. 2 and Table 4). However, the association of physical activity with fat mass appeared weaker among participants with CKD, with a $p$-value for interaction that was of borderline statistical significance $(p=0.045$ without accounting for multiple comparisons).

\section{Discussion}

In this study, we found that higher levels of physical activity, measured using gold standard accelerometry, were associated with greater insulin sensitivity, lower fat mass, and lower serum triglyceride concentration. These associations were independent of demographics, cardiovascular disease, and eGFR and were similar when physical activity was evaluated as average daily movement (CPM) or as proportion of time spent non-sedentary. Participants with CKD tended to have lower physical activity and insulin sensitivity and higher fat mass and serum triglyceride concentrations, compared with healthy control subjects. Nonetheless, associations of physical activity with metabolic health outcomes were generally similar among participants with and without CKD.

Prior studies have shown that patients with CKD are less physically active than the general population, an observation that we also made in our study [23]. Moreover, among people with CKD, greater physical activity has been associated with decreased risks of CKD progression, cardiovascular events, and mortality [24-26]. In the general population, physical activity has been correlated with reduced risks of diabetes, stroke, coronary artery disease, congestive heart failure, and hypertension $[14,23,24,27,28]$. In this context, our results help define a plausible biologic basis for the potential clinical benefits of physical activity in CKD. Specifically, our study provides precise, quantitative data demonstrating independent associations of physical activity with major components of metabolic health that may mediate effects of physical activity on long-term clinical outcomes. Our results are complementary to and consistent with those of the cohort studies noted above and with exercise training studies suggesting that increased activity decreases adiposity and inflammation in CKD [29].

Insulin sensitivity is an important measure of metabolic health, with lower sensitivity (insulin resistance) comprising a core component of the metabolic syndrome [30]. This study demonstrated that physical activity is directly correlated with insulin sensitivity, using gold standard measurements of each. The association of physical activity with insulin sensitivity was significant after adjustment for demographic variables, prevalent cardiovascular disease, and eGFR, but somewhat attenuated with further adjustment for fat mass. This observation suggests that 
Table 2 Metabolic health measurements in SUGAR, by level of physical activity

\begin{tabular}{|c|c|c|c|c|}
\hline & \multicolumn{3}{|l|}{ Physical activity } & \multirow[b]{2}{*}{$p$-value } \\
\hline & $\begin{array}{l}\text { Tertile } 1 \\
(\leq 375 \text { CPM) }\end{array}$ & $\begin{array}{l}\text { Tertile } 2 \\
(375<\text { CPM } \leq 631)\end{array}$ & $\begin{array}{l}\text { Tertile } 3 \\
(>631 \text { CPM) }\end{array}$ & \\
\hline Insulin sensitivity $(\mathrm{mg} / \mathrm{min}) /(\mu \mathrm{U} / \mathrm{mL})$ & $3.8(1.5)$ & $4.5(2.8)$ & $5.2(1.8)$ & 0.009 \\
\hline Fasting glucose (mg/dL) & $103.2(8.9)$ & $103.2(10.0)$ & $98.8(8.6)$ & 0.12 \\
\hline Fasting insulin (uU/mL) & $11.1(5.4)$ & $9.7(5.6)$ & $6.6(4.6)$ & 0.004 \\
\hline HOMA-IR & $2.8(1.9)$ & $2.4(1.6)$ & $1.5(1.1)$ & 0.003 \\
\hline Fat mass (kg) & $35.7(13.3)$ & $31.2(12.4)$ & $26.3(11.3)$ & 0.03 \\
\hline $\mathrm{BMI}\left(\mathrm{kg} / \mathrm{m}^{2}\right)$ & $31.8(6.2)$ & $29.6(5.3)$ & $26.4(5.3)$ & 0.002 \\
\hline CRP (mg/dL), median & $0.2(0.2-0.4)$ & $0.2(0.1-0.6)$ & $0.1(0.1-0.3)$ & 0.07 \\
\hline $\mathrm{HDL}(\mathrm{mg} / \mathrm{dL})$ & $52.2(28.0)$ & $50.6(14.4)$ & $61.2(18.4)$ & 0.06 \\
\hline Triglycerides (mg/dL), median & $135.0(114.0-191.0)$ & $120.0(73.0-163.0)$ & $85.0(58.5-120.2)$ & 0.007 \\
\hline Systolic blood pressure $(\mathrm{mm} \mathrm{Hg})$ & $135.1(14.4)$ & $130.7(12.1)$ & $124.3(17.2)$ & 0.046 \\
\hline Diastolic blood pressure $(\mathrm{mm} \mathrm{Hg})$ & $78.0(9.6)$ & $79.9(8.4)$ & $77.4(11.3)$ & 0.61 \\
\hline
\end{tabular}

Entries are mean (SD), except as noted. Some values were missing for Matsuda $(N=1), C R P H(N=1)$ and Fat Mass $(N=4)$. $C P M$ counts per minute, $C R P$ high sensitivity C-reactive protein, $B M I$ body mass index, $H D L$ high density lipoprotein cholesterol

the relationship of physical activity with insulin sensitivity is mediated partly, but not wholly, through reduced adiposity. The hyperinsulinemic-euglycemic clamp measures total body insulin sensitivity, which mostly reflects skeletal muscle insulin sensitivity because endogenous glucose production by the liver is nearly or fully suppressed at the insulin infusion rate we applied [4]. It is therefore possible that our observed association of physical activity with insulin sensitivity reflects beneficial effects of exercise on muscle metabolism. It is also possible that insulin sensitivity is influenced by other comorbidities not accounted for in this study. The association of physical activity with insulin sensitivity was significant when evaluated within CKD participants only, and we did not observe an interaction of physical activity with CKD status, suggesting that

Table 3 Associations of physical activity with metabolic health outcomes in SUGAR

\begin{tabular}{|c|c|c|c|c|}
\hline & Unadjusted & Model 1 & Model 2 & Model 3 \\
\hline \multicolumn{5}{|l|}{ Outcomes: } \\
\hline Insulin sensitivity $(\mathrm{mg} / \mathrm{min}) /(\mu \mathrm{U} / \mathrm{mL})$ & $1.0(0.4,1.5)$ & $0.8(0.2,1.4)$ & $0.9(0.2,1.5)$ & $0.7(0.0,1.4)$ \\
\hline$P$ Value & 0.0003 & 0.009 & 0.006 & 0.04 \\
\hline Fat mass (kg) & $-6.3(-10.3,-2.2)$ & $-8.2(-12.8,-3.6)$ & $-8.0(-12.9,-3.1)$ & NA \\
\hline$P$ Value & 0.002 & 0.0005 & 0.001 & NA \\
\hline BMI $\left(\mathrm{kg} / \mathrm{m}^{2}\right)$ & $-2.7(-4.6,-0.8)$ & $-3.6(-5.8,-1.5)$ & $-3.6(-5.9,-1.3)$ & NA \\
\hline$P$ Value & 0.005 & 0.0007 & 0.002 & NA \\
\hline CRP (\% difference) & $-33(-51,-7)$ & $-32(-50,-6)$ & $-24(-48,13)$ & $-5(-37,43)$ \\
\hline$P$ Value & 0.01 & 0.02 & 0.17 & 0.83 \\
\hline $\mathrm{HDL}(\mathrm{mg} / \mathrm{dL})$ & $5.6(-2.3,13.5)$ & $6.6(-2.0,15.3)$ & $6.8(-0.8,14.4)$ & $5.5(-1.5,12.5)$ \\
\hline$P$ Value & 0.17 & 0.13 & 0.08 & 0.12 \\
\hline Triglycerides (mg/dL) & $-39.9(-72.4,-7.5)$ & $-45.0(-76.2,-13.9)$ & $-37.9(-71.9,-3.9)$ & $-22.7(-57.0,11.6)$ \\
\hline$P$ Value & 0.02 & 0.005 & 0.03 & 0.20 \\
\hline Systolic BP (mm Hg) & $-5.8(-10.7,-1.0)$ & $-4.5(-9.1,0.0)$ & $-3.0(-8.0,2.0)$ & $0.2(-4.6,5.1)$ \\
\hline$P$ Value & 0.02 & 0.053 & 0.24 & 0.93 \\
\hline Diastolic BP (mm Hg) & $0.3(-2.9,3.5)$ & $-1.2(-4.1,1.7)$ & $-1.1(-4.2,1.9)$ & $-0.5(-3.5,2.6)$ \\
\hline$P$ Value & 0.87 & 0.42 & 0.47 & 0.77 \\
\hline
\end{tabular}

Entries are the difference $(95 \% \mathrm{Cl})$ in the outcome associated with a doubling in accelerometry mean counts per minute. Model 1 adjusts for age, sex, and race (white/black/other). Model 2 additionally adjusts for cardiovascular disease and eGFR. For HDL and triglycerides outcomes, Model 2 additionally adjusts for statins, fibrates, and niacin medications; for BP outcomes, Model 2 additionally adjusts for the number of hypertension medications. Model 3 adjusts for Model 2 variables plus fat mass. $B M I$ body mass index, $C R P$ C-reactive protein, $H D L$ high density lipoprotein cholesterol, $B P$ blood pressure 
Table 4 Associations of physical activity with metabolic health outcomes in SUGAR, by CKD status

\begin{tabular}{|c|c|c|c|c|c|}
\hline \multirow[t]{2}{*}{ Dependent variable } & \multicolumn{2}{|l|}{ CKD } & \multicolumn{2}{|l|}{ Non CKD } & \multirow[b]{2}{*}{$P$ value for Interaction } \\
\hline & Mean $(S D)^{b}$ & $\overline{\text { Adjusted difference }(95 \% \mathrm{Cl})^{\mathrm{a}}}$ & $\overline{\text { Mean }(S D)^{b}}$ & Adjusted difference $(95 \% \mathrm{Cl})^{\mathrm{a}}$ & \\
\hline Insulin sensitivity $(\mathrm{mg} / \mathrm{min}) /(\mu \mathrm{U} / \mathrm{mL})$ & $4.1(2.1)$ & $0.8(0.2,1.4)$ & $5.2(2.0)$ & $1.0(0.1,1.9)$ & 0.73 \\
\hline Fat mass (kg) & $32.0(11.4)$ & $-4.9(-10.2,0.4)$ & $29.4(14.8)$ & $-13.2(-20.2,-6.2)$ & 0.045 \\
\hline BMI $\left(\mathrm{kg} / \mathrm{m}^{2}\right)$ & $30.0(5.5)$ & $-2.0(-4.5,0.6)$ & $28.0(6.8)$ & $-6.3(-9.4,-3.2)$ & 0.03 \\
\hline CRP (percent difference) & $0.3(2.6)$ & $-11(-44,43)$ & $0.1(2.8)$ & $-41(-66,2)$ & 0.26 \\
\hline $\mathrm{HDL}(\mathrm{mg} / \mathrm{dL})$ & $52.4(22.4)$ & $2.2(-8.2,12.6)$ & $58.7(18.9)$ & $13.9(5.8,22.0)$ & 0.07 \\
\hline Triglycerides (mg/dL) & $153.2(91.6)$ & $-39.8(-90.3,10.8)$ & $99.6(66.8)$ & $-30.7(-57.9,-3.5)$ & 0.76 \\
\hline Systolic BP (mmHg) & $134.5(14.3)$ & $-0.2(-6.3,6.0)$ & $122.6(13.9)$ & $-7.5(-13.1,-2.0)$ & 0.07 \\
\hline Diastolic BP (mmHg) & $79.6(9.5)$ & $1.3(-2.4,5.1)$ & $76.4(10.1)$ & $-5.2(-8.5,-1.9)$ & 0.007 \\
\hline
\end{tabular}

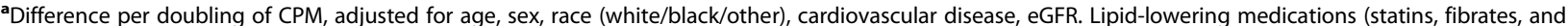
niacin medications, included for HDL-cholesterol and triglycerides only), and antihypertensive medications (yes/no and number of antihypertensive medications, for systolic and diastolic BP only), as in Model 2 of Table 3

${ }^{b}$ Entry for CRP is geometric mean (SD)

physical activity may be associated with improving insulin sensitivity.

The inverse association of physical activity with fat mass appeared weaker in participants with versus without CKD. Associations of adiposity with mortality have also been reported to be weaker in people with versus without CKD [31, 32], suggesting that CKD may alter both the causes and consequences of obesity. However, our observed interaction was of borderline statistical significance, particularly considering the fact that we tested multiple potential interactions, and may not represent a true difference by CKD status. Adiposity may promote cardiovascular disease and progression of kidney disease through inflammation and impaired lipoprotein metabolism [33-35]. Therefore, physical activity may reduce adiposity, which may lead to a reduction in cardiovascular disease and progression of kidney disease. Physical activity was also correlated with serum triglyceride concentration. Triglycerides may have direct lipotoxic actions on kidney and vascular tissue and may promote kidney and vascular disease through increased inflammation [36, 37].

We did not observe statistically significant associations of physical activity with inflammation or blood pressure. Other studies have shown inverse correlations of physical ability [27] measured by questionnaire with physical activity [14] to reduced levels of CRP. We may not have shown a significant association because of limited power and the use of only one inflammatory marker. Also, we examined levels of CRP in the blood, while the mechanism of action might be in relevant tissues like adipose and muscle. BP may not have shown correlation due to physical activity being only one of many possible influences affecting BP, making it difficult to find a signal among much noise. We may have been able to detect associations with more precise $24 \mathrm{~h}$ ambulatory BP measurements. We observed trends toward expected associations with CRP and BP that may have been statistically significant in a larger study.
Physical activity (CPM) and active time yielded similar metabolic outcome associations, with adjusted HAP yielding weaker associations. This suggests that HAP may misclassify physical activity and that studies that used HAP may have had more impressive associations had physical activity been directly measured by accelerometer. Although physical activity (CPM) and active time yielded similar outcome associations, it is difficult to determine which is more beneficial due to the small study size and the correlation between these two aspects of movement within our study. A larger study has examined the concept in relationship with mortality in greater detail and found a decrease in mortality with increased physical activity and duration of activity [24].

Several factors contribute to the strengths and limitations of our study. Accelerometry is the gold standard for objectively measuring physical activity as it is more precise and less subject to recall bias than questionnaires, which have been used in most prior studies $[18,38]$. The hyperinsulinemic-euglycemic clamp is a gold standard method for the measurement of insulin sensitivity and as such is a strength of our study. However, the accelerometer does not account for potential inaccuracies caused by missing data due to patients not wearing the devices. Also the wear period may not accurately reflect a patient's extended physical activity. Our study is further strengthened by our examination of a clinic-based population of importance to practicing nephrologists and the evaluation of a comprehensive set of metabolic outcomes that may be key mediators of cardiovascular and renal risk in CKD patients. The cross-sectional design of the study limits our ability to ascertain long-term clinical outcomes or discern causal relationships. The modest size of our study may increase the influence of outliers, reduce statistical power, and increase the chance that factors important to this population were missed. 


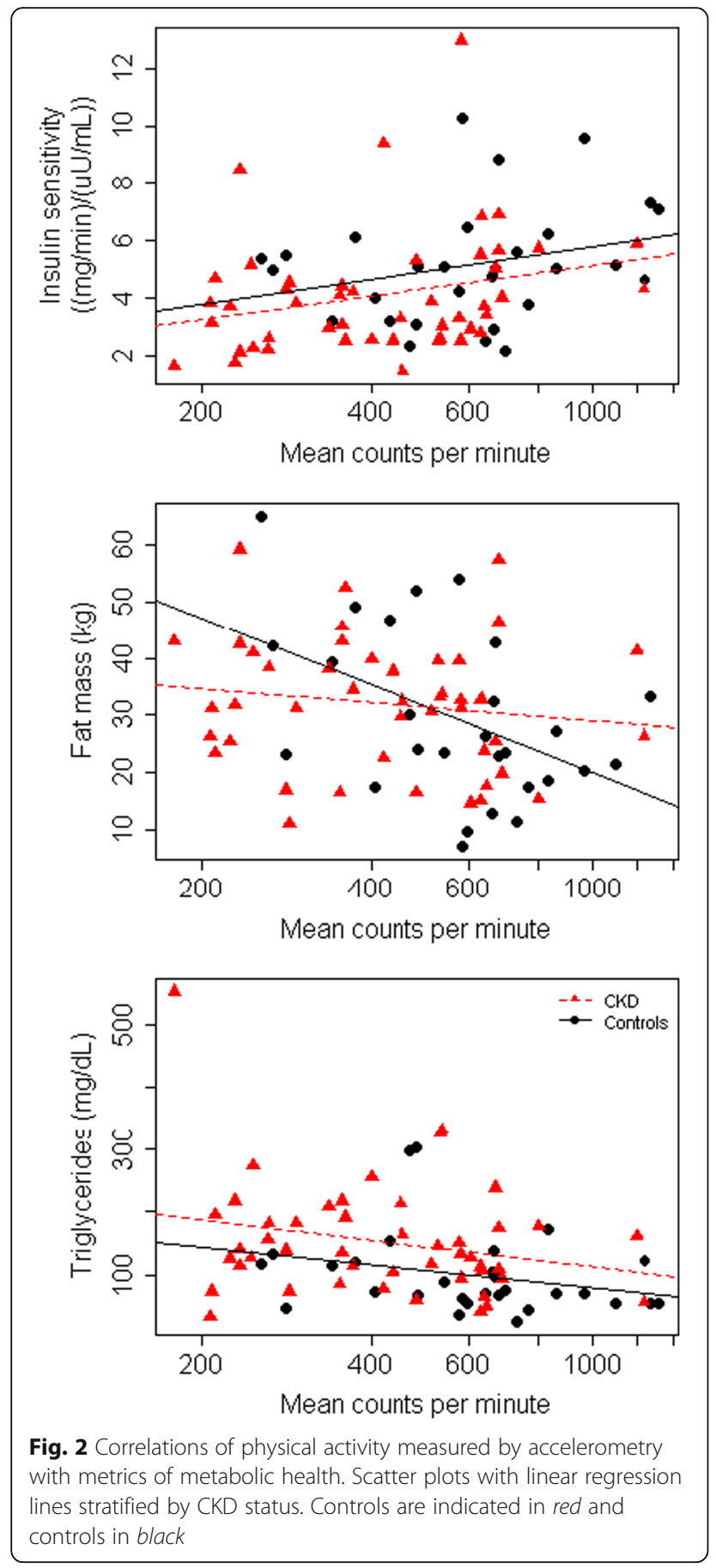

\section{Conclusion}

In conclusion, this study suggests that greater physical activity is associated with improved metabolic health for patients with moderate-severe CKD by increasing insulin sensitivity and reducing adiposity and serum triglycerides. This study identifies insulin sensitivity, adiposity, and dyslipidemia as logical intermediate targets for short-term physical activity trials that assess what types of physical activity may best promote metabolic health in CKD. Larger studies are needed to examine the long term effects of physical activity and its potential health benefits for patients with CKD.

\section{Additional file}

Additional file 1: Supplementary Material Physical Activity and Metabolic Health in CKD. Figure S1 and Tables S1-5). (DOCX 63 kb)

\section{Abbreviations}

AER: Albumin excretion rate; BP: Blood pressure; CKD: Chronic kidney disease; CPM: Counts per minute; CRP: C-reactive protein; CVD: Cardiovascular disease; eGFR: Estimated glomerular filtration rate; HAP: Human activity profile; SD: Standard deviation; SI: Insulin sensitivity; SUGAR: Study of glucose and insulin in renal disease

\section{Acknowledgements}

We thank Laura Curtin and Nicole Robinson for their contributions to data collection, and John Ruzinski and Denise Rock for their help with the assays.

\section{Funding}

SUGAR was funded by R01DK087726 from the National Institute of Diabetes and Digestive and Kidney Diseases with additional support from ULTR000423, P01DK017047, P30DK035816, R01DK088762, and R01DK099199. This project was supported in part by the Department of Veterans Affairs. This project was also made possible by the National Center for Advancing Translational Sciences, National Institutes of Health, through Grant TL1 TR000422.

\section{Availability of data and materials}

Data will be shared publicly only after completion of analyses addressing the specific aims of R01DK087726, the primary funding source of SUGAR.

\section{Authors' contributions}

WB and IdB conceived and designed the study. $\mathrm{CH}, \mathrm{KU}$, and IdB acquired the data. WB, LZ, and IdB analyzed the data. All authors interpreted the data, were involved in the drafting and revising of the manuscript, and gave final approval to the manuscript. IdB is accountable for all aspects of the work, including ensuring that questions related to the accuracy or integrity of the work are appropriately investigated and resolved.

\section{Competing interests}

The authors declare that they have no competing interests.

\section{Consent for publication}

Not applicable.

\section{Ethics approval and consent to participate}

The SUGAR study was approved by the University of Washington Institutional Review Board (protocol \#39275). All participants provided written informed consent.

\section{Author details}

'University of Washington School of Medicine, Seattle, WA, USA. ${ }^{2}$ Division of Nephrology and Kidney Research Institute, University of Washington, Seattle, WA, USA. ${ }^{3}$ VA Puget Sound Health Care System, Seattle, WA, USA. ${ }^{4}$ Division of Metabolism, Endocrinology, and Nutrition, University of Washington, Seattle, WA, USA.

Received: 2 April 2016 Accepted: 15 November 2016 Published online: 22 November 2016

\section{References}

1. Matsushita K, van der Velde M, Astor BC, Woodward M, Levey AS, de Jong PE, Coresh J, Gansevoort RT, Consortium CKDP. Association of estimated glomerular filtration rate and albuminuria with all-cause and cardiovascular mortality in general population cohorts: a collaborative meta-analysis. Lancet. 2010;375(9731):2073-81.

2. Pham $\mathrm{H}$, Utzschneider $\mathrm{KM}$, de Boer $\mathrm{H}$. Measurement of insulin resistance in chronic kidney disease. Curr Opin Nephrol Hypertens. 2011;20(6):640-6. 
3. DeFronzo RA, Alvestrand A, Smith D, Hendler R, Hendler E, Wahren J. Insulin resistance in uremia. J Clin Invest. 1981;67(2):563-8.

4. de Boer $\mid H$, Zelnick L, Afkarian M, Ayers E, Curtin L, Himmelfarb J, Ikizler TA, Kahn SE, Kestenbaum B, Utzschneider K. Impaired Glucose and Insulin Homeostasis in Moderate-Severe CKD. J Am Soc Nephrol. 2016.

5. Fliser D, Pacini G, Engelleiter R, Kautzky-Willer A, Prager R, Franek E, Ritz E. Insulin resistance and hyperinsulinemia are already present in patients with incipient renal disease. Kidney Int. 1998;53(5):1343-7.

6. Siew ED, Ikizler TA. Determinants of insulin resistance and its effects on protein metabolism in patients with advanced chronic kidney disease. Contrib Nephrol. 2008;161:138-44.

7. Wheatcroft SB, Williams IL, Shah AM, Kearney MT. Pathophysiological implications of insulin resistance on vascular endothelial function. Diabet Med. 2003;20(4):255-68.

8. Dogra G, Irish A, Chan D, Watts G. Insulin resistance, inflammation, and blood pressure determine vascular dysfunction in CKD. Am J Kidney Dis. 2006:48(6):926-34.

9. Rutter MK, Meigs JB, Sullivan LM, D'Agostino RB, Wilson PW. Insulin resistance, the metabolic syndrome, and incident cardiovascular events in the Framingham Offspring Study. Diabetes. 2005;54(11):3252-7.

10. Hedblad B, Nilsson P, Engstrom G, Berglund G, Janzon L. Insulin resistance in non-diabetic subjects is associated with increased incidence of myocardial infarction and death. Diabet Med. 2002;19(6):470-5.

11. Kurella M, Lo JC, Chertow GM. Metabolic Syndrome and the Risk for Chronic Kidney Disease among Nondiabetic Adults. J Am Soc Nephrol. 2005;16(7):2134-40.

12. Meckling KA, Sherfey R. A randomized trial of a hypocaloric high-protein diet, with and without exercise, on weight loss, fitness, and markers of the Metabolic Syndrome in overweight and obese women. Appl Physiol Nutr Metab. 2007;32(4):743-52.

13. Hagnäs MP, Cederberg H, Mikkola I, Ikäheimo TM, Jokelainen J, Laakso M, Härkönen P, Peitso A, Rajala U, Keinänen-Kiukaanniemi S. Reduction in metabolic syndrome among obese young men is associated with exerciseinduced body composition changes during military service. Diabetes Res Clin Pract. 2012;98(2):312-9.

14. Robinson-Cohen C, Littman AJ, Duncan GE, Weiss NS, Sachs MC, Ruzinski J, Kundzins J, Rock D, de Boer $H$, Ikizler TA, et al. Physical activity and change in estimated GFR among persons with CKD. J Am Soc Nephrol. 2014;25(2):399-406.

15. Hawkins MS, Sevick MA, Richardson CR, Fried LF, Arena VC, Kriska AM. Association between physical activity and kidney function: National Health and Nutrition Examination Survey. Med Sci Sports Exerc. 2011;43(8):1457-64.

16. DeFronzo RA, Tobin JD, Andres R. Glucose clamp technique: a method for quantifying insulin secretion and resistance. Am J Phys. 1979;237(3):E214-23.

17. Masse LC, Fuemmeler BF, Anderson CB, Matthews CE, Trost SG, Catellier DJ, Treuth M. Accelerometer data reduction: a comparison of four reduction algorithms on select outcome variables. Med Sci Sports Exerc. 2005;37(11 Suppl):S544-54.

18. Robinson-Cohen C, Littman AJ, Duncan GE, Roshanravan B, Ikizler TA, Himmelfarb J, Kestenbaum BR. Assessment of physical activity in chronic kidney disease. J Ren Nutr. 2013;23(2):123-31.

19. Davidson M, de Morton N. A systematic review of the Human Activity Profile. Clin Rehabil. 2007;21(2):151-62.

20. Matthews DR, Hosker JP, Rudenski AS, Naylor BA, Treacher DF, Turner RC. Homeostasis model assessment: insulin resistance and beta-cell function from fasting plasma glucose and insulin concentrations in man. Diabetologia. 1985;28(7):412-9.

21. Inker LA, Schmid CH, Tighiouart H, Eckfeldt JH, Feldman HI, Greene T, Kusek JW, Manzi J, Van Lente F, Zhang YL, et al. Estimating glomerular filtration rate from serum creatinine and cystatin C. N Engl J Med. 2012;367(1):20-9.

22. R: A language and environment for statistical computing.http://www.Rproject.org/. Accessed 1 July 2015.

23. Beddhu S, Baird BC, Zitterkoph J, Neilson J, Greene T. Physical activity and mortality in chronic kidney disease (NHANES III). Clin J Am Soc Nephrol. 2009;4(12):1901-6.

24. Beddhu S, Wei G, Marcus RL, Chonchol M, Greene T. Light-Intensity Physical Activities and Mortality in the United States General Population and CKD Subpopulation. Clin J Am Soc Nephrol. 2015;10(7):1145-53.

25. Chen IR, Wang SM, Liang CC, Kuo HL, Chang CT, Liu JH, Lin HH, Wang IK, Yang YF, Chou CY, et al. Association of walking with survival and RRT among patients with CKD stages 3-5. Clin J Am Soc Nephrol. 2014;9(7):1183-9.

26. Xu H, Huang X, Arnlöv J, Cederholm T, Stenvinkel P, Lindholm B, Risérus U, Carrero JJ. Clinical correlates of insulin sensitivity and its association with mortality among men with CKD stages 3 and 4. Clin J Am Soc Nephrol. 2014:9(4):690-7.

27. Roshanravan B, Robinson-Cohen C, Patel KV, Ayers E, Littman AJ, de Boer $\mathbb{H}_{\text {, }}$ Ikizler TA, Himmelfarb J, Katzel LI, Kestenbaum B, et al. Association between physical performance and all-cause mortality in CKD. J Am Soc Nephrol. 2013;24(5):822-30

28. Ricardo AC, Anderson CA, Yang W, Zhang X, Fischer MJ, Dember LM, Fink JC, Frydrych A, Jensvold NG, Lustigova E, et al. Healthy lifestyle and risk of kidney disease progression, atherosclerotic events, and death in CKD: findings from the Chronic Renal Insufficiency Cohort (CRIC) Study. Am J Kidney Dis. 2015;65(3):412-24.

29. Johansen $K L$, Painter P. Exercise in individuals with CKD. Am J Kidney Dis. 2012:59(1):126-34

30. Grundy SM, Cleeman JI, Daniels SR, Donato KA, Eckel RH, Franklin BA, Gordon DJ, Krauss RM, Savage PJ, Smith SC, et al. Diagnosis and management of the metabolic syndrome: an American Heart Association/ National Heart, Lung, and Blood Institute scientific statement: Executive Summary. Crit Pathw Cardiol. 2005;4(4):198-203.

31. Kalantar-Zadeh K, Streja E, Kovesdy CP, Oreopoulos A, Noori N, Jing J, Nissenson AR, Krishnan M, Kopple JD, Mehrotra R, et al. The obesity paradox and mortality associated with surrogates of body size and muscle mass in patients receiving hemodialysis. Mayo Clin Proc. 2010;85(11):991-1001.

32. Park J, Ahmadi SF, Streja E, Molnar MZ, Flegal KM, Gillen D, Kovesdy CP, Kalantar-Zadeh K. Obesity paradox in end-stage kidney disease patients. Prog Cardiovasc Dis. 2014;56(4):415-25.

33. Amann K, Wanner C, Ritz E. Cross-talk between the kidney and the cardiovascular system. J Am Soc Nephrol. 2006;17(8):2112-9.

34. Agarwal S, Shlipak MG, Kramer H, Jain A, Herrington DM. The association of chronic kidney disease and metabolic syndrome with incident cardiovascular events: multiethnic study of atherosclerosis. Cardiol Res Pract. 2012;2012:806102.

35. Shlipak MG, Fried LF, Crump C, Bleyer AJ, Manolio TA, Tracy RP, Furberg CD, Psaty BM. Elevations of inflammatory and procoagulant biomarkers in elderly persons with renal insufficiency. Circulation. 2003:107(1):87-92.

36. Prasad GV. Metabolic syndrome and chronic kidney disease: Current status and future directions. World J Nephrol. 2014;3(4):210-9.

37. Wahba IM, Mak RH. Obesity and obesity-initiated metabolic syndrome: mechanistic links to chronic kidney disease. Clin J Am Soc Nephrol. 2007;2(3):550-62.

38. Pham H, Robinson-Cohen C, Biggs ML, Ix JH, Mukamal KJ, Fried LF, Kestenbaum B, Siscovick DS, de Boer $\mathrm{H}$. Chronic kidney disease, insulin resistance, and incident diabetes in older adults. Clin J Am Soc Nephrol. 2012:7(4):588-94.

\section{Submit your next manuscript to BioMed Central and we will help you at every step:}

- We accept pre-submission inquiries

- Our selector tool helps you to find the most relevant journal

- We provide round the clock customer support

- Convenient online submission

- Thorough peer review

- Inclusion in PubMed and all major indexing services

- Maximum visibility for your research

Submit your manuscript at www.biomedcentral.com/submit
) Biomed Central 